\title{
Transferrin in Korean Children with Attention Deficit Hyperactivity Disorder
}

\author{
Ho Jang Kwon ${ }^{1,2}$, Myung Ho Lim ${ }^{1,3}$, Mina Ha ${ }^{1,2}$, Eun Jung Kim¹, \\ Seung Jin Yoo', Jong Wan Kim ${ }^{4}$ and Ki Chung Paik ${ }^{1,3}$ \\ ${ }^{1}$ Environmental Health Center, Dankook University Hospital, Cheonan, Korea \\ 2Department of Preventive Medicine, College of Medicine, Dankook University, Cheonan, Korea \\ ${ }^{3}$ Department of Psychiatry, College of Medicine, Dankook University, Cheonan, Korea \\ ${ }^{4}$ Department of Laboratory Medicine, College of Medicine, Dankook University, Cheonan, Korea
}

Objective The aim of the present study was to investigate the relationship between iron, ferritin, transferrin, total iron binding capacity (TIBC), hemoglobin, mean corpuscular volume (MCV) mean corpuscular hemoglobin (MCH), and mean corpuscular hemoglobin concentration (MCHC) in children with ADHD.

Methods The sample consisted of 48 ADHD children and sex and age matched control children (a couple of 28 boys, 22 girls; age 6-8 years; mean \pm SD, 6.98 \pm 0.39 ). We diagnosed ADHD according to DSM-IV. ADHD symptoms were evaluated subjectively with Conners' Parent Rating Scales, Dupaul Parent ADHD Rating Scales. Subjects with ADHD and control were evaluated the hematology test including the iron, transferrin, MCV etc. Paired t test were used to evaluate the relation of a lot of hematology findings between ADHD and control group.

Results The serum iron, ferritin, transferrin, TIBC, hemoglobin, $\mathrm{MCV}, \mathrm{MCH}$, and $\mathrm{MCHC}$ of ADHD group were respectively $80.92 \pm 33.33$ $\mathrm{ug} / \mathrm{dL}, 35.81 \pm 16.59 \mathrm{ng} / \mathrm{mL}, 248.42 \pm 44.15 \mathrm{mg} / \mathrm{dL}, 351.69 \pm 102.13 \mathrm{ug} / \mathrm{dL}, 12.78 \pm 0.71 \mathrm{~g} / \mathrm{dL}, 82.94 \pm 2.58 \mathrm{fL}, 27.18 \pm 1.12 \mathrm{uug}, 32.79 \pm 1.12 \%$. Otherwise the serum iron, ferritin, transferrin, TIBC, hemoglobin, $\mathrm{MCV}, \mathrm{MCH}$, and $\mathrm{MCHC}$ of control group were respectively $82.04 \pm$ $28.14 \mathrm{ug} / \mathrm{dL}, 37.05 \pm 18.28 \mathrm{ng} / \mathrm{mL}, 266.27 \pm 25.40 \mathrm{mg} / \mathrm{dL}, 352.77 \pm 89.54 \mathrm{ug} / \mathrm{dL}, 12.77 \pm 0.70 \mathrm{~g} / \mathrm{dL}, 81.81 \pm 2.96 \mathrm{fL}, 26.69 \pm 0.99 \mathrm{uug}, 32.66 \pm 0.96$ $\%$. A significant difference were found in the transferrin $(\mathrm{t}=2.63, \mathrm{p}=0.011), \mathrm{MCV}(\mathrm{t}=2.19, \mathrm{p}=0.034)$, and $\mathrm{MCH}(\mathrm{t}=2.18, \mathrm{p}=0.034)$.

Conclusion These results suggested that lower transferrin levels might be related with ADHD symptoms.

Psychiatry Investig 2011;8:366-371

Key Words ADHD, Transferrin, Hematology, Child.

\section{INTRODUCTION}

Attention Deficit Hyperactivity Disorder (ADHD) is a common childhood neuropsychiatric disorder characterized by behavioral problems such as attention deficit, hyperactivity and impulsivity. It has a prevalence of $2-7.6 \%$ among children of school age in Korea. ${ }^{1-3}$ Although genetic factors are known to be the dominant cause of ADHD, its etiology is recently considered more complex. It is likely that genetic factors interact with en-

Received: January 19, 2011 Revised: April 12, 2011

Accepted: May 15, 2011 Available online: November 25, 2011

$\triangle$ Correspondence: Myung Ho Lim, MD

Department of Psychiatry, Environmental Health center, College of Medicine, Dankook University, 359 Manghyang Rho, Cheonan 300-714, Korea

Tel: +82-10-2640-1498, Fax: +82-41-561-3007, E-mail: paperose@dku.edu

(a) This is an Open Access article distributed under the terms of the Creative Commons Attribution Non-Commercial License (http://creativecommons.org/licenses/by$\mathrm{nc} / 3.0$ ) which permits unrestricted non-commercial use, distribution, and reproduction in any medium, provided the original work is properly cited. vironmental factors, in addition to complex interactions between dopamine and noradrenalin. ${ }^{4,5}$ Iron is known to regulate dopamine and noradrenalin production as the coenzyme of tyrosine hydroxylase, itself a monoamine oxidase.

In 1997, Saver et al. ${ }^{6}$ studied the correlation between iron deficiency and ADHD. They reported that supplementation of 5 $\mathrm{mg} / \mathrm{kg}$ of iron to $14 \mathrm{ADHD}$ children for 30 days resulted in increased serum ferritin level and reduced Conner's ADHD rating scale. Konofal et al. ${ }^{7}$ asserted that ADHD is primarily caused by reduced serum iron concentration. Serum iron levels were found to be significantly decreased in ADHD children: of out 53 ADHD children studied, serum ferritin in $84 \%$ of whom was less than $30 \mathrm{ng} / \mathrm{mL}$, compared to $18 \%$ in 27 control subjects. Furthermore, this study demonstrated correlation between low serum ferritin levels and symptoms as well as cognitive damage in ADHD children. The outcomes of some studies are contrary to the observation that administration of iron sup- 
plementation to ADHD children with low iron levels resulted in positive improvement in ADHD. Millichap et al. ${ }^{8}$ measured the levels of serum ferritin in 68 ADHD children, and showed that $74 \%$ of children had serum ferritin concentration of less than $50 \mathrm{ng} / \mathrm{mL}$, $44 \%$ less than $30 \mathrm{ng} / \mathrm{mL}$, and $18 \%$ less than 20 $\mathrm{ng} / \mathrm{mL}$, which were not significantly different from that of the normal control group. They also reported an absence of significant difference in the degree and frequency of symptoms between 12 ADHD children with serum ferritin concentration lower than $20 \mathrm{ng} / \mathrm{mL}$, and $12 \mathrm{ADHD}$ children with serum ferritin concentration higher than $60 \mathrm{ng} / \mathrm{mL}$. Recently, Konofal et al. ${ }^{9}$ conducted a study that entailed 12 weeks of oral supplementation of iron at $80 \mathrm{mg} / \mathrm{d}$ to $18 \mathrm{ADHD}$ children diagnosed according to the Diagnostic and Statistical Manual of Mental Disorders Fourth Edition (DSM-IV). ${ }^{11}$ Significant difference was observed in ADHD scale and global clinical impression in ADHD children, compared to 5 children administered with placebo.

Since iron concentration can be affected on age, sex, race and socioeconomic factors, careful attention should be taken when measuring serum iron. In addition, the normal range of serum iron concentration varies with ethnicity and the standard intake required for normal growth varies between countries. Supportive measure for ADHD children to complement drug therapy have been reported in other countries, but not in Korea.

The aim of this study was to compare the hematological findings, including serum iron and ferritin, in Korean ADHD children with that of age- and sex-matched children without ADHD.

\section{METHODS}

\section{Subjects}

Forty-eight $(\mathrm{n}=48)$ children diagnosed with ADHD according to the DSM-IV by a child psychiatrist at the Dankook University Hospital were enrolled in this study. Subjects were excluded from the study if there was any evidence of conduct disorder, mood disorder, anxiety disorder, Tourette's disorder, pervasive development disorder, mental retardation (IQ <70) and neurological disorders, including epilepsy. None of the children who participated in the study has ever undergone drug treatment. In this study, the controls and the patients were collected from general elementary schools after receiving consents. The sex and age were matched between the control group and the patient group. Those who had medical diseases, central nervous system diseases such as epilepsy, and child psychiatric disorders such as $\mathrm{ADHD}$, childhood developmental disorder, mental retardation, depressive disorder, or behavioral disorder were excluded from the subjects. Each subject and his or her caregivers were provided adequate counseling on the study and the associated investigations. Informed consent was obtained prior to study entry. The study was also approved by the Hospital Ethics Committee. None of the children was taking iron supplements or multivitamins with iron at the time of the study. The parents could choose to opt out of the study but none of the parents refused to participate.

\section{Assessment}

A blood test was carried out with the patient group and the control group, including the serum iron, ferritin, transferrin, total iron binding capacity (TIBC), hemoglobin, mean corpuscular volume (MCV), mean corpuscular hemoglobin (MCH), and mean corpuscular hemoglobin concentration (MCHC), etc. The therapist performed assessment of basic history and physical examination such as general blood laboratory test, consulting a pediatrist about the cases of iron level decrease. On the day of visiting the hospital, the child psychiatrist performed clinical interview as well as Kovac's Children's Depression Inventory $(\mathrm{CDI})^{12}$, State Anxiety Inventory (SAIC), Trait Anxiety Inventory (TAIC) ${ }^{13}$ and Dupaul Attention Deficit Hyperactivity Disorder Rating Sales (K-ARS) ${ }^{14}$ as well as the questionnaire survey regarding the pregnancy, infancy, developmental history and anamnesis of the children with the parents. In addition, a professional clinical psychologist performed a comprehensive psychological test, including intelligence test, on each subject. A child psychiatrist evaluated ADHD symptoms and co-existing illnesses through personal interview with each subject.

\section{Kovac's Children's Depression Inventory}

The CDI was developed by Kovacs to measure the degree of children's depression by modifying the Beck's depression inventory for the children at the age between 6-14. ${ }^{12}$ The CDI contains a total of 27 questions and the subject is asked to evaluate his or her own mood state in the previous two week in the a self-report form. In the self-report form, scores between 0 to 2 are given for each question, and the total scores are between 0 to 54 . Cho and Lee investigated the control group distribution with 288 subjects in the 4, 5 and 6 grades in the elementary schools in Seoul and the result showed that the mean score was 14.72 $( \pm 7.13)$ with no significant difference in the mean score between the male students of 14.16 and the female students of 15.36. ${ }^{15}$ Cho and Lee ${ }^{15}$ presented the score over 22 as the mild depressed state, over 26 as the middle depressed state, and over 29 as the severe depressed state.

\section{Spielberger State-Trait Anxiety Inventory}

This is a useful assessment tool to measure anxiety clinically. It is useful in identify clinically anxious group and psychiatric patients and it also has the advantage to measure the anxious state of normal adults without psychiatric disorder. It was developed by Spielberger et al. ${ }^{13}$ and translated into 
Korean version by $\mathrm{Kim}^{16}$, and the reliability and validity were studied. The anxiety inventory for children is composed of a total of ${ }^{20}$ questions prepared by modifying the trait anxiety scale for adults. The rating score 1 is given to 'it rarely happens.' score 2 to 'sometimes', and score 3 to 'often.' The total score ranges from 20 to 60 . Cho and Choi 17 evaluated the reliability of the Korean State Anxiety Inventory for Children and derived the mean score of trait anxiety $31.96( \pm 7.13)$ with 522 elementary school students at the fourth, fifth and sixth grades. ${ }^{17}$ In the case of TAIC scale, the scores 39-42 indicate a little high trait anxiety, scores 43-46 indicate a considerably high trait anxiety, and scores 47 or higher indicate very high trait anxiety. In the case of state anxiety inventory, the mean score was 33.27 ( \pm 7.67$)$, while it was $36.44( \pm 8.48)$ at the time immediately before exams.

\section{Korean version of Dupaul Attention Deficit Hyperactivity Disorder Rating Sales}

Being developed by Dupaul based on the DSM-IV diagnostic criteria for ADHD, Dupaul ADHD Rating Scales is used for both parent and teacher assessment scale for child behavior. ${ }^{14}$ This Scales with 18 items is proved for its validity in differentiating children with ADHD from those without ADHD, and also designed effective to differentiating three subtypes of ADHD: predominantly inattentive, predominantly hyperactive-impulsive, and combined hyperactiveimpulsive and inattentive. Each item scores 1 to 3 and the score above 2 is considered abnormal in terms of child development. Odd-numbered items are to measure inattentiveness and even-numbered items are to measure hyperactivity and impulsivity. Domestic standardization has been achieved by Kim et al. ${ }^{14}$ and children with ADHD may score above 19 by parents or/and 18 by teachers.

\section{Computerized Attention Deficit-Hyperactivity Disorder Diagnostic System}

ADS is a computerized program being widely used to diagnose ADHD and assess the continuous performance function in children with attention-deficit or hyperactivity. As one of the most popular Continuous Performance Tests in Korea, ADS was developed and standardized by Shin et al. ${ }^{18}$ It has two components: visual and auditory. ADS assesses general attention ability and its detailed evaluation index includes omission errors, commission errors, hit reaction time mean, hit reaction time standard deviation, attentiveness, and risk taking. Omission errors indicate the number of times the target is presented but the subject does not respond to the target. It is a measure of inattentiveness. Commission errors indicate the number of times responses are given to non-targets and it measures the degrees of response prevention and impulsivity. Mean hit reaction time is the average speed of correct response and it measures the speed of response and information processing. Hit reaction time deviation is the standard deviation of hit reaction time and it measures response speed consistency and attentional flexibility. A score of above 70 in omission errors, commission errors, or hit reaction time standard deviation is suggestive of continuous attention deficit and that clinically ADHD is suspected.

\section{Statistical analysis}

We performed independent $t$ test for age, chi-square test for sex, and paired t test to compare the results of control group and ADHD group through iron, ferritin, transferrin, TIBC, hemoglobin, $\mathrm{MCV}, \mathrm{MCH}$, and $\mathrm{MCHC}$ and Abbreviated Conners Parent-Teacher Rating Scale, K-ARS, CDI, TAIC, and SAIC in children with ADHD. We performed correlation analysis for iron, ferritin, transferrin, TIBC, K-ARS, ADHD diagnosis, IQ, CDI, TAIC, SAIC, ADS in children with ADHD. SPSS PC software (version 15.0) was used for the statistical analysis and the significance level was set to the p value less than 0.05 .

\section{RESULTS}

The blood test showed that the hemoglobin level lower than $12 \mathrm{~g} / \mathrm{dL}$ was found in nine children, but only one showed the ferritin level lower than $15 \mathrm{ng} / \mathrm{mL}$ and iron level lower than $50 \mathrm{ug} / \mathrm{dL}$. The children who showed iron deficiency were transferred to a child hemato-oncologist.

The sample consisted 48 ADHD children and sex and age matched control children (a couple of 23 boys and 20 girls; age 6-9 years; mean \pm S.D. 7.53 \pm 0.63 ). The mean of age, K-ARS, CDI, TAIC, SAIC of ADHD group were respectively $7.53 \pm 0.63$, $26.12 \pm 6.99,12.64 \pm 6.46,30.82 \pm 6.72,31.64 \pm 6.14$. Otherwise the mean of age, K-ARS, CDI, TAIC, SAIC of control group were respectively $7.62 \pm 0.69,2.05 \pm 3.70,5.47 \pm 4.94,26.20 \pm 5.99$, $27.89 \pm 6.57$. A significant difference were found in the mean of K-ARS $(\mathrm{t}=18.26, \mathrm{p}=0.000), \mathrm{CDI}(\mathrm{t}=5.93, \mathrm{p}=0.000)$, TAIC $(\mathrm{t}=3.16$, $\mathrm{p}=0.003)$, SAIC $(\mathrm{t}=2.99, \mathrm{p}=0.005)$ (Table 1$)$.

The serum iron, ferritin, transferrin, TIBC, hemoglobin, $\mathrm{MCV}, \mathrm{MCH}$, and MCHC of ADHD group were respectively $80.92 \pm 33.33 \mathrm{ug} / \mathrm{dL}, 35.81 \pm 16.59 \mathrm{ng} / \mathrm{mL}, 248.42 \pm 44.15 \mathrm{mg} /$ $\mathrm{dL}, 351.69 \pm 102.13 \mathrm{ug} / \mathrm{dL}, 12.78 \pm 0.71 \mathrm{~g} / \mathrm{dL}, 82.94 \pm 2.58 \mathrm{fL}$, $27.18 \pm 1.12$ uug, $32.79 \pm 1.12 \%$. Otherwise the serum iron, ferritin, transferrin, TIBC, hemoglobin, $\mathrm{MCV}, \mathrm{MCH}$, and $\mathrm{MCHC}$ of Contol group were respectively $82.04 \pm 28.14 \mathrm{ug} / \mathrm{dL}, 37.05 \pm$ $18.28 \mathrm{ng} / \mathrm{mL}, 266.27 \pm 25.40 \mathrm{mg} / \mathrm{dL}, 352.77 \pm 89.54 \mathrm{ug} / \mathrm{dL}$, $12.77 \pm 0.70 \mathrm{~g} / \mathrm{dL}, 81.81 \pm 2.96 \mathrm{fL}, 26.69 \pm 0.99 \mathrm{uug}, 32.66 \pm 0.96$ $\%$. The mean \pm SD of various measures related to iron metabolism and hematological variables are summarized in Table 2. A significant difference were found in the transferrin $(\mathrm{t}=-2.63$, $\mathrm{p}=0.011), \operatorname{MCV}(\mathrm{t}=2.19, \mathrm{p}=0.034)$, and $\mathrm{MCH}(\mathrm{t}=2.18, \mathrm{p}=0.034)$ (Table 2). It is suggestive finding that Low transferrin levels 
Table 1. Comparison the rating scales of with between ADHD and control group

\begin{tabular}{|c|c|c|c|c|c|c|c|c|}
\hline & \multicolumn{3}{|c|}{$\operatorname{ADHD}(\mathrm{N}=48)$} & \multicolumn{3}{|c|}{ Control $(\mathrm{N}=48)$} & \multirow{2}{*}{$\mathrm{t}$} & \multirow{2}{*}{$\mathrm{p}$} \\
\hline & Mean \pm SD & Min & Max & Mean \pm SD & Min & Max & & \\
\hline K-ARS & $26.12 \pm 6.99$ & 10 & 44 & $2.05 \pm 3.70$ & 0 & 17 & 18.26 & 0.000 \\
\hline $\mathrm{CDI}$ & $12.64 \pm 6.46$ & 5 & 30 & $5.47 \pm 4.94$ & 0 & 21 & 5.93 & 0.000 \\
\hline TAIC & $30.82 \pm 6.72$ & 21 & 44 & $26.20 \pm 5.99$ & 20 & 43 & 3.16 & 0.003 \\
\hline SAIC & $31.64 \pm 6.14$ & 21 & 48 & $27.89 \pm 6.57$ & 20 & 44 & 2.99 & 0.005 \\
\hline
\end{tabular}

${ }^{*} \mathrm{p}<0.05$, paired t-test. K-ARS: Dupaul attention deficit hyperactivity disorder rating sales, ${ }^{14} \mathrm{CDI}$ : Kovac's children's depression inventory, ${ }^{12}$ SAIC: state anxiety inventory, TAIC: trait anxiety inventory, ${ }^{13}$ ADHD: attention deficit hyperactivity disorder, SD: standard deviation

Table 2. Comparison of with iron, ferritin, transferrin, total iron binding capacity (TIBC), hemoglobin, mean corpuscular volume (MCV) mean corpuscular hemoglobin $(\mathrm{MCH})$, and mean corpuscular hemoglobin concentration (MCHC) between ADHD and control group

\begin{tabular}{|c|c|c|c|c|c|c|c|c|c|}
\hline & \multirow{2}{*}{ Reference value } & \multicolumn{3}{|c|}{$\operatorname{ADHD}(\mathrm{N}=48)$} & \multicolumn{3}{|c|}{ Control $(\mathrm{N}=48)$} & \multirow{2}{*}{$\mathrm{t}$} & \multirow{2}{*}{$\mathrm{p}$} \\
\hline & & Mean \pm SD & Min & Max & Mean \pm SD & Min & $\operatorname{Max}$ & & \\
\hline Serum iron (ug/dL) & $37-158$ & $80.92 \pm 33.33$ & 14 & 157 & $82.04 \pm 28.14$ & 19 & 153 & -0.18 & 0.858 \\
\hline Ferritin (ng/mL) & $15-150$ & $35.81 \pm 16.59$ & 13.40 & 81.50 & $37.05 \pm 18.28$ & 13.00 & 88.60 & -0.36 & 0.722 \\
\hline Transferrin (mg/dL) & $200-360$ & $248.42 \pm 44.15$ & 105 & 316 & $266.27 \pm 25.40$ & 221 & 336 & -2.63 & 0.011 \\
\hline TIBC (ug/dL) & $281-364$ & $351.69 \pm 102.13$ & 260 & 828 & $352.77 \pm 89.54$ & 252 & 821 & 0.05 & 0.957 \\
\hline Hemoglobin $(\mathrm{g} / \mathrm{dL})$ & & $12.78 \pm 0.71$ & 11.50 & 14.40 & $12.77 \pm 0.70$ & 10.50 & 14.10 & -0.83 & 0.411 \\
\hline $\mathrm{MCV}(\mathrm{fL})$ & $80-92$ & $82.94 \pm 2.58$ & 76.30 & 88.80 & $81.81 \pm 2.96$ & 75.30 & 87.10 & 2.19 & 0.034 \\
\hline $\mathrm{MCH}$ (uug) & $27-32$ & $27.18 \pm 1.12$ & 25.10 & 29.90 & $26.69 \pm 0.99$ & 24.50 & 29.00 & 2.18 & 0.034 \\
\hline $\mathrm{MCHC}(\%)$ & $31-36$ & $32.79 \pm 1.12$ & 30.60 & 35.70 & $32.66 \pm 0.96$ & 30.40 & 34.50 & 0.56 & 0.580 \\
\hline
\end{tabular}

${ }^{\star} \mathrm{p}<0.05$, paired t-test. TIBC: total iron binding capacity, MCV: mean corpuscular volume, MCH: mean corpuscular hemoglobin, MCHC: mean corpuscular hemoglobin concentration, ADHD: attention deficit hyperactivity disorder, SD: standard deviation

were associated with ADHD diagnosis. While iron, ferritin, TIBC, hemoglobin, MCV, MCH, and MCHC were not significantly related with $\mathrm{ADHD}$ diagnosis. We added the information about the correlations among the hematologic laboratory data (iron, ferritin, transferrin, hemoglobin, TIBC) and K-ARS, ADS, CDI, TAIC, SAIC, and IQ to the Table 3. A significant Pearson's correlation was found in the transferrin and $\mathrm{ADHD}$ diagnosis $(\mathrm{t}=-0.24, \mathrm{p}<0.05)($ Table 3$)$.

\section{DISCUSSION}

About 25\% of the total body iron is present as stored iron in the form of ferritin around two thirds, approximately $0.2 \%$ of the total iron in the body is bound to the transport protein transferrin in the plasma. ${ }^{19}$ A reduced ferritin concentration is an early indication of the depletion of iron stores long before the transferrin concentration increases or plasma iron levels fall. Plasma transferrin transports iron either to iron storage depots or to organs which require iron, e.g. the bone marrow. Of the three analyses - iron, transferrin and ferritin the latter is most easily biased by these factors since iron stores may be severely depleted before any clinical signs are evident. ${ }^{19}$

Correlation between iron deficiency and cranial nerve abnormality has been demonstrated by clinical studies. ${ }^{20}$ In 1963 ,
Holowach et al. ${ }^{21}$ showed that iron deficiency anemia occurred in $23 \%$ of children who experienced 'breath holding spells', and later reported partial improvement by administering ferrous sulfate supplement to these children. With respect to the pathophysiological studies of iron, a recent animal experiment demonstrated that iron deficiency alters the absorption and decomposition of monoamine by reducing the density and activity of monoamine and dopamine receptors. ${ }^{22,23}$ In addition, Konofal et al. ${ }^{9}$ assumed that low ferritin concentration may affect dopamine concentration in the brain and hence symptoms of ADHD.

Improvement in ADHD symptoms was seen in a study conducted by Sever et al. ${ }^{6}$ However, they found improvement in the $\mathrm{ADHD}$ scale for the parents, but not in that for the teachers, indicative that the placebo effect could not be excluded. It must be emphasized that ADHD symptoms were assessed 30 days after commencing iron supplementation in that study, which appeared to be too early. In fact, recovery of learning disorder only became evident 2 months after normal hemoglobin levels had been restored in that study. ${ }^{6}$ We attempted to overcome the drawback of previous studies by employing clinical scales and other objective testing tools, such as ADS, in addition to conducting interviews to compare symptoms. We found reduced transferrin levels in children with $\mathrm{ADHD}$, although we did not 
Table 3. Correlation of with iron, ferritin, transferrin, total iron binding capacity (TIBC), K-ARS, ADHD diagnosis, IQ, CDI, TAIC, SAIC, ADS in children with ADHD

\begin{tabular}{|c|c|c|c|c|c|c|c|c|c|c|c|c|}
\hline & Iron & TIBC & Transferrin & Ferritin & K-ARS & IQ & CDI & TAIC & SAIC & ADS-I & ADS-H & ADS-R \\
\hline Iron & 1 & -0.118 & -0.106 & 0.046 & -0.025 & -0.212 & 0.093 & 0.024 & 0.069 & -0.022 & -0.074 & -0.020 \\
\hline TIBC & & 1 & 0.192 & -0.053 & 0.085 & 0.085 & 0.092 & 0.179 & 0.068 & -0.008 & 0.098 & -0.007 \\
\hline Transferrin & & & 1 & $-0.247^{*}$ & -0.082 & -0.042 & -0.056 & 0.162 & 0.107 & 0.089 & -0.047 & -0.095 \\
\hline Ferritin & & & & 1 & -0.050 & -0.017 & 0.025 & -0.081 & -0.016 & -0.115 & 0.029 & -0.039 \\
\hline K-ARS & & & & & 1 & -0.123 & $0.620^{* *}$ & $0.519^{* *}$ & $0.380^{* *}$ & 0.096 & 0.178 & $0.312^{* *}$ \\
\hline IQ & & & & & & 1 & -0.128 & -0.128 & 0.091 & -0.164 & -0.060 & -0.061 \\
\hline CDI & & & & & & & 1 & $0.0459^{* *}$ & $0.383^{* *}$ & 0.097 & 0.071 & $0.317^{* *}$ \\
\hline TAIC & & & & & & & & 1 & $0.443^{* *}$ & 0.152 & -0.039 & 0.044 \\
\hline SAIC & & & & & & & & & 1 & -0.032 & -0.120 & -0.074 \\
\hline ADS-O & & & & & & & & & & 1 & $0.529^{* *}$ & $0.562^{* *}$ \\
\hline ADS-C & & & & & & & & & & & 1 & $0.695^{* *}$ \\
\hline ADS-R & & & & & & & & & & & & 1 \\
\hline
\end{tabular}

${ }^{*} \mathrm{p}<0.05,{ }^{* *} \mathrm{p}<0.01$. TIBC: total iron binding capacity, K-ARS: Dupaul attention deficit hyperactivity disorder rating sales, ${ }^{14} \mathrm{CDI}:$ Kovac's children's depression inventory, ${ }^{12}$ TAIC: trait anxiety inventory, SAIC: state anxiety inventory, ${ }^{13}$ ADS-O: computerized attention deficit hyperactivity disorder diagnostic system-omission error, ADS-C: computerized computerized attention deficit hyperactivity disorder diagnostic system-comission error, ADS-R: computerized attention deficit hyperactivity disorder diagnostic system - standard deviation of response time, ADHD: attention deficit hyperactivity disorder, IQ: intelligence quotient

administer iron supplement. In this study, the ferritin concentration was not different between the two group, which is different to some extent from the result of other studies that the ferritin level was increased in the ADHD group. A difference in transferrin between the two groups was found in our study. It was known that transferrin is more stable in blood than ferritin that reflects stored iron. However, since this study was conducted in a small scale, and the two indices are greatly fluctuated by the blood measurement methods, further studies may need to be conducted. As such, we anticipate improved clinical symptoms following iron supplementation in ADHD children with reduced iron levels in future clinical trials.

Some studies have demonstrated learning disorder in children associated with symptoms of anemia, and in children with mild iron deficiency without symptoms of anemia. In a largescale study of 5,398 children, Haltermann et al. ${ }^{24}$ reported that the risk of scoring low in mathematics is twice as high in children with iron deficiency, compared to those with normal serum iron levels, regardless of the development of anemia. Brunner et al. ${ }^{25}$ observed significant cognitive improvement when $650 \mathrm{mg}$ of ferrous sulfate supplement was administered twice daily for 8 weeks to girls aged between 13 and 18 with learning disorder. However, the latter study did not assess behavioral symptoms, which is a requisite in ADHD assessment.

The prevalence of ADHD is higher among males and in the adolescence. Thus, the sex and age characteristics can have a great effect. Considering this, our study was evaluated by matching the age and sex of the patient group and the control group with each other. Not all methodologies are calibrated in rela- tion to the same primary standard, which is one reason for different results with different test systems.

The restless leg syndrome shares similar clinical patterns with $\mathrm{ADHD}$ and is frequently associated with $\mathrm{ADHD}$. A study recently demonstrated iron supplement improved both ADHD and restless leg syndrome. ${ }^{26}$ In our study, however, the symptoms were purely secondary to $\mathrm{ADHD}$, since the restless leg syndrome is not frequently associated with $\mathrm{ADHD}$, in contrast to conduct disorder, anxiety and depressive disorders.

Iron supplement will be a complementary therapeutic adjunct in the treatment of ADHD, if there is genuine correlation between ADHD and iron. However, the efficacy of iron supplement to existing therapeutic intervention for ADHD must be demonstrated in a large-scale study in the future. Since the use of methylphenidate, which is prescribed by child psychiatrists in Korea, is currently restricted in children below the age of 5 by the Food and Drug Administration in the United States, iron supplement may be efficacious in the treatment of ADHD in this age group. ${ }^{27}$ According to a recent study, iron exhibited synergistic effects with methylphenidate and amphetamine, and was effective in the treatment of ADHD associated with restless leg syndrome for which methylphenidate is inefficacious. These results suggest various ways to apply iron supplementation in ADHD.

\section{Acknowledgments}

This study was financially supported by the Ministry of Environment, Korea. 


\section{REFERENCES}

1. Cho SC, Shin YO. Prevalence of disruptive behavior disorders. Korean J Child Adolesc Psychiatry 1994;5:141-149.

2. Kim JY, Ahn DH, Shin YJ. An epidemiological study of attention-deficit hyperactivity disorder and learning disabilities in a rural area. J Korean Neuropsychiatr Assoc 1999;38:784-793.

3. Pyo KS, Park SH, Kim SH, Cho YR, Kim HR, Moon KR. The Prevalence of Attention Deficit Hyperactivity Disorder in Urban Elementary School Children. Kwangju: Department of Psychiatry, Chosun University; 2001.

4. Eaves LJ, Silberg JL, Meyer JM, Maes HH, Simonoff E, Pickles A, et al. Genetics and developmental psychopathology: 2. The main effects of genes and environment on behavioral problems in the Virginia Twin Study of Adolescent Behavioral Development. J Child Psychol Psychiatry 1997;38:965-980.

5. Biederman J, Faraone S. Attention-deficit hyperactivity disorder. Lancet 2005;366:237-248.

6. Sever Y, Ashkenazi A, Tyano S, Weizman A. Iron treatment in children with attention deficit hyperactivity disorder. A preliminary report. Neuropsychobiology 1997;35:178-180.

7. Konofal E, Lecendreux M, Arnulf I, Mouren MC. Iron deficiency in children with attention-deficit/hyperactivity disorder. Arch Pediatr Adolesc Med 2004;158:1113-1115.

8. Millichap JG, Yee MM, Davidson SI. Serum ferritin in children with attention-deficit hyperactivity disorder. Pediatr Neurol 2006;34:200203.

9. Konofal E, Lecendreux M, Deron J, Marchand M, Cortese S, Zaïm M, et al. Effects of iron supplementation on attention deficit hyperactivity disorder in children. Pediatr Neurol 2008;38:20-26.

10. Hollowell JG, van Assendelft OW, Gunter EW, Lewis BG, Najjar M, Pfeiffer C, et al. Hematological and iron-related analytes--reference data for persons aged 1 year and over; United States, 1988-94. Vital Health Stat 11 2005;247:1-156.

11. American Psychiatric Association. Diagnostic and Statistical Manual of Mental Disorders, Fourth Edition. Washington, DC: American Psychiatric Press; 1994.

12. Kovacs M. The Children's Depression Inventory: A Self-Rated Depression Scale for School-Aged Youngsters. Pittsburgh, PA: University of Pittsburgh; 1983.

13. Spielberger CD, Gorsuch RL, Lushene RE. Manual for the State-Trait
Anxiety Inventory. Pal Alto, CA: Consulting Psychologist Press; 1970.

14. So YK, Noh JS, Kim YS, Ko SG, Koh YJ. The reliability and validity of Korean parent and teacher ADHD rating scale. J Korean Neuropsychiatr Assoc 2002;41:283-289.

15. Cho SC, Lee YS. Development of the Korean form of the Kovacs' Childhood Depression Inventory. J Korean Neuropsychiatr Assoc 1990; 29:943-956.

16. Kim JT. Relationship between Trait Anxiety and Sociability: Focused on STAI of Spielberger. Master Thesis. Seoul: Graduate School of Korea University; 1978.

17. Cho SC, Choi JS. Development of the Korean form of the State-Trait Anxiety Inventory for children. Seoul J Psychiatry 1989;14:150-157.

18. Shin MS, Cho SC, Chun SY, Hong KE. A study of the development and standardization of ADHD diagnostic system. Korean J Child Adolesc Psychiatry 2000;11:91-99.

19. Hinzmann RD. Ferritin and transferrin in iron deficiency and overload. Immundiagn Today 1999;12:1-4.

20. Yager JY, Hartfield DS. Neurologic manifestations of iron deficiency in childhood. Pediatr Neurol 2002;27:85-92.

21. Holowach J, Thurston DL. Breath-holding spells and anemia. N Engl J Med 1963;268:21-23.

22. Beard JL, Chen Q, Connor J, Jones BC. Altered monoamine metabolism in caudate-putamen of iron-deficient rats. Pharmacol Biochem Behav 1994;48:621-624.

23. Burhans MS, Dailey C, Beard Z, Wiesinger J, Murray-Kolb L, Jones $\mathrm{BC}$, et al. Iron deficiency: differential effects on monoamine transporters. Nutr Neurosci 2005;8:31-38.

24. Halterman JS, Kaczorowski JM, Aligne CA, Auinger P, Szilagyi PG. Iron deficiency and cognitive achievement among school-aged children and adolescents in the United States. Pediatrics 2001;107:1381-1386.

25. Bruner AB, Joffe A, Duggan AK, Casella JF, Brandt J. Randomised study of cognitive effects of iron supplementation in non-anaemic iron-deficient adolescent girls. Lancet 1996;348:992-996.

26. Cortese S, Konofal E, Lecendreux M, Arnulf I, Mouren MC, Darra F, et al. Restless legs syndrome and attention-deficit/hyperactivity disorder: a review of the literature. Sleep 2005;28:1007-1013.

27. Konofal E, Cortese S, Lecendreux M, Arnulf I, Mouren MC. Effectiveness of iron supplementation in a young child with attention-deficit/hyperactivity disorder. Pediatrics 2005;116:e732-e734. 